International Journal of Environmental Research and

Public Health

ISSN 1660-4601

www.mdpi.com/journal/ijerph

Addendum

\title{
Addendum: Han, Y.; Grogan-Kaylor, A.; Delva, J.; Xie, Y. Estimating the Heterogeneous Relationship Between Peer Drinking and Youth Alcohol Consumption in Chile Using Propensity Score Stratification. Int. J. Environ. Res. Public Health 2014, 11, 11879-11897
}

\author{
Yoonsun Han ${ }^{1, *}$, Andrew Grogan-Kaylor ${ }^{2}$, Jorge Delva ${ }^{2}$ and Yu Xie ${ }^{3}$ \\ 1 Department of Child Psychology and Education, Sungkyunkwan University, \\ 25-2 Sungkyunkwan-ro, Jongno-gu, Seoul 110-745, Korea \\ 2 School of Social Work, University of Michigan, 1080 South University Avenue, Ann Arbor, \\ MI 48109, USA; E-Mails: agrogan@umich.edu (A.G.-K.); jdelva@umich.edu (J.D.) \\ 3 Institute for Social Research, University of Michigan, 426 Thompson Street, Ann Arbor, MI 48109, \\ USA; E-Mail: yuxie@umich.edu \\ * Author to whom correspondence should be addressed; E-Mail: yoonsunhan@skku.edu; \\ Tel.: +82-2-760-0526; Fax: +82-2-760-0525.
}

Received: 14 January 2015 / Accepted: 27 January 2015 / Published: 30 January 2015

The authors wish to update the Acknowledgments in their paper published in International Journal of Environmental Research and Public Health [1], doi:10.3390/ijerph111111879, website: http://www.mdpi.com/1660-4601/11/11/11879.

\section{Acknowledgements}

We are extremely grateful to the youth and their families in Santiago, Chile for taking the time to participate in this study. This study received support from the BK21PLUS Program through the Ministry of Education of the Republic of Korea (22B20130000013), U.S. National Institute on Drug Abuse (R01 DAD21181), National Institute of Child Health and Human Development (R01-HD-074603-01), and the Vivian A. and James L. Curtis School of Social Work Research and Training Center, University of Michigan. 


\section{Reference}

1. Han, Y.; Grogan-Kaylor, A.; Delva, J.; Xie, Y. Estimating the heterogeneous relationship between peer drinking and youth alcohol consumption in Chile using propensity score stratification. Int. J. Environ. Res. Public Health 2014, 11, 11879-11897.

(C) 2015 by the authors; licensee MDPI, Basel, Switzerland. This article is an open access article distributed under the terms and conditions of the Creative Commons Attribution license (http://creativecommons.org/licenses/by/4.0/). 